\title{
Whole Parathyroid Hormone Measurement
}

National Cancer Institute

\section{Source}

National Cancer Institute. Whole Parathyroid Hormone Measurement. NCI Thesaurus.

Code C103451.

The determination of the amount of the whole parathyroid hormone (consisting of amino acids 1-84) in a sample. 